\title{
Plastic Instability in ISO 5832-9 High-nitrogen Austenitic Stainless Steel
}

\author{
José Hélio Oliveira Santos SOBRINHO, ${ }^{1)}$ Samuel Filgueiras RODRIGUES, ${ }^{1) *}$ Eden Santos SILVA, ${ }^{1)}$ Gedeon Silva \\ REIS, ${ }^{1)}$ Regina Célia SOUSA, ${ }^{2)}$ Valdemar Silva LEAL ${ }^{1)}$ and José Manuel Rivas MERCURY ${ }^{1)}$
}

1) Department of Mechanic and Materials, Federal Institute of Education, Science and Technology of Maranhão, Av. Getúlio Vargas, n 04, Monte Castelo, 65030-005 São Luís - MA, Brazil.

2) Department of Physics, Federal University of Maranhão, Av. dos Portugueses, University City, 1966, Bacanga, 65080-805 São Luís - MA, Brazil.

(Received on September 6, 2014; accepted on November 13, 2014)

\begin{abstract}
ISO 5832-9 high-nitrogen austenitic stainless steel has shown promising results in the fabrication of temporary and permanent orthopedic prostheses, exhibiting better mechanical strength and corrosion resistance than the traditional ISO 5832-1 (ASTM F-138) steel. Recent studies have revealed that this alloy possesses unique properties, such as high mechanical strength and corrosion resistance and the presence of second phase particles ( $Z$ phase) in the matrix. However, it is not known how the microstructural and mechanical properties and the corrosion rate are correlated in regions of industrial processability of this alloy during hot forming. In this study, continuous and interrupted isothermal hot torsion tests were performed after solubilization heat treatment at $1473 \mathrm{~K}$ for $300 \mathrm{~s}$, with temperature intervals varying from 1273 to $1473 \mathrm{~K}$ and strain rates ranging from 0.05 to $5 \mathrm{~s}^{-1}$. The purpose of these tests was to investigate the alloy's workability and stress corrosion rate by means of electrochemical impedance spectroscopy (EIS) and to characterize its microstructure by optical microscopy. The results indicate that the yield stress is sensitive to the strain parameters. The peak stress decreases with increasing temperature and decreasing strain rate, with a high rate of dynamic recovery, with elongated grains generating areas of stress build-up. These regions of plastic instability present a higher degree of corrosion than as-received samples. The regions of high temperature and low strain rate exhibit good workability with a refined final microstructure of dynamically recrystallized grains.
\end{abstract}

KEY WORDS: stainless steel; workability; plastic instability; processing maps; corrosion.

\section{Introduction}

Austenitic stainless steels have good corrosion resistance and a combination of mechanical properties that is suitable for many industrial applications. However, when these steels are used for orthopedic implants, they may present several problems such as susceptibility to localized corrosion when in contact with body fluids and tissue, and regions of plastic instability under industrial processing conditions. ISO 5832-9 high-nitrogen austenitic stainless steel specified by the ISO 5832-9 standard, with typical composition of $22 \mathrm{Cr}-10 \mathrm{Ni}-2.5 \mathrm{Mo}-0.4 \mathrm{Nb}-0.35 \mathrm{~N}$, has shown promising results in the fabrication of temporary and permanent orthopedic prostheses, exhibiting better properties than the ISO 5832-1 steel traditionally used (ASTM F-138). ${ }^{1,2}$ )

Recent research has revealed that this alloy possesses unique properties, such as high mechanical strength and corrosion resistance and the presence of second phase particles ( $\mathrm{Z}$ phase) in the matrix. ${ }^{2,3)}$ However, it is not known how the microstructural and mechanical properties and the corrosion rate are correlated in regions of industrial processability of

\footnotetext{
* Corresponding author: E-mail: samuel.filgueiras@ifma.edu.br DOI: http://dx.doi.org/10.2355/isijinternational.55.670
}

this alloy during the hot forming of orthopedic parts. $\left.{ }^{4}\right)$

During the fabrication of implants, metallic materials are subjected to a hot forging process accompanied by microstructural evolution associated with dynamic softening phenomena that play an important role in determining the alloy's final microstructure and properties. The microstructural mechanisms in hot deformation of metals and alloys are generally governed by stacking fault energy (SFE) and their mechanical behavior is controlled by three phenomena: work hardening (HW), dynamic recovery (DRV) and dynamic recrystallization (DRX). ${ }^{5-7}$ )

In some materials with high SFE, such as Aluminum (Al), $0.160 \mathrm{~J} / \mathrm{m}^{2}$, the balance between hardening and dynamic recovery is expressed by a threshold on the plastic flow curve. ${ }^{89}$ However, in materials with low to moderate SFE, such as austenitic stainless steels, e.g., AISI 304L, the SFE is about $0.018 \mathrm{~J} / \mathrm{m}^{2}$, while in AISI 305 steel it is about 0.034 $\mathrm{J} / \mathrm{m}^{2}$, in AISI $310 \mathrm{~S}$ steel about $0.094 \mathrm{~J} / \mathrm{m}^{2}$, and in AISI 316 steel about $0.078 \mathrm{~J} / \mathrm{m}^{2}{ }^{10}$ ) The contribution of $\mathrm{Ni}, \mathrm{Cr}, \mathrm{Mn}$ and Mo to the SFE of the matrix of an austenitic stainless steel was estimated, and the SFE for ISO 5832-9 steel was calculated as $0.0687 \mathrm{~J} / \mathrm{m}^{2},{ }^{11}$ ) the kinetics of dynamic recovery is low, and dynamic recrystallization is initiated in a critical condition of strain energy build-up associated 
Table 1. Chemical composition of ISO 5832-9 steel (mass\%).

\begin{tabular}{cccccccccccc}
\hline $\mathrm{C}$ & $\mathrm{Si}$ & $\mathrm{Mn}$ & $\mathrm{Ni}$ & $\mathrm{Cr}$ & $\mathrm{Mo}$ & $\mathrm{S}$ & $\mathrm{P}$ & $\mathrm{N}$ & $\mathrm{Cu}$ & $\mathrm{Nb}$ & $\mathrm{Fe}$ \\
\hline 0.035 & 0.37 & 4.04 & 10.6 & 20.3 & 2.47 & 0.001 & 0.022 & 0.36 & 0.06 & 0.29 & bal. \\
\hline
\end{tabular}

with softening on the plastic flow curve. Thus, the effect of dynamic recrystallization on the mechanical, microstructural and corrosion parameters in terms of working conditions are of paramount importance, since they depend on the material's chemical composition, its deformation mode, and the deformation conditions. ${ }^{12)}$

These usual deformation conditions in metallurgical processing determine the regions of best workability, which are represented by processing maps that are developed using engineering systems, continuum mechanics, thermodynamic principles of irreversible processes, and plastic flow criteria. ${ }^{13-15)}$ These regions are correlated with specific microstructural processes that occur during hot working, when the best areas for processing the material are identified in the DRX and DRV domains. Information from processing maps can be integrated effectively in the design and optimization of industrial processes of orthopedic metal alloys. While the temperature and strain rate in the domain of maximum workability are chosen as optimized process parameters that should be controlled to ensure that local temperature and strain rate values do not enter undesirable regimes such as flow instability, ${ }^{16,17)}$ it is necessary to find a safe domain at higher rates of stress that increases productivity.

Due to the complexity of the microstructure and use of this material, it is important to understand its constitutive behavior, characterizing its final properties and understanding the microstructure that develops during deformation within the regions of workability in order to identify the best processing parameters. This study aims to evaluate the degree of corrosion in the regions of hot workability in the industrial processing of this alloy, where recent researches have revealed the presence of regions of plastic instability.

\section{Experimental Procedure}

The material used in this study was ISO 5832-9 highnitrogen stainless steel, whose chemical composition is described in Table 1, supplied by Villares Metals S.A., São Paulo, Brazil. This commercial alloy was previously hotrolled into bars of $20 \mathrm{~mm}$ diameter, annealed at $1303 \mathrm{~K}$ for $3600 \mathrm{~s}$, and cooled in water. The mechanical tests were performed on a computerized TMIV hot torsion machine at the laboratory of mechanical and materials engineering (DMM) of the Federal Institute of Maranhão (IFMA). The test specimens were machined to a working effective diameter of $8 \mathrm{~mm}$ and gauge length of $12 \mathrm{~mm}$, and heated in an infrared radiation furnace coupled to the testing machine. The temperature was measured using $\mathrm{K}$ type thermocouple (chromel-alumel) attached to the test specimen. Data were collected using a program that imposes parametric tests such as temperature, strain rate, waiting time and amount of effort, according to Von Mises criteria. ${ }^{18)}$ The samples were heated from room temperature to a soak temperature of $1473 \mathrm{~K}$ at a rate of $10 \mathrm{~K} / \mathrm{s}$, held at this temperature for $300 \mathrm{~s}$, cooled to the test temperature at a rate of $2 \mathrm{~K} / \mathrm{s}$, held
Table 2. Conditions chosen for the interrupted isothermal torsion tests, according to the maps developed by SILVA ${ }^{19}$.

\begin{tabular}{clccc}
\hline Samples & \multicolumn{1}{c}{$\varepsilon$} & $\mathrm{T}(\mathrm{K})$ & Rate $\left(\mathrm{s}^{-1}\right)$ & Domain \\
\hline $\mathrm{A} 1$ & 0.5 & 1323 & 0.05 & Instab. \\
$\mathrm{A} 2$ & 0.75 & 1273 & 1.0 & Instab. \\
$\mathrm{A} 3$ & 1.3 & 1273 & 0.1 & Instab. \\
$\mathrm{A} 4$ & 2.0 & 1273 & 0.1 & Instab. \\
$\mathrm{A} 5$ & 4.0 & 1323 & 0.5 & Workab. \\
$\mathrm{A} 6$ & 2.0 & 1473 & 1.0 & Workab \\
$\mathrm{A} 7$ & 4.0 & 1323 & 0.1 & Workab \\
\hline
\end{tabular}

there for $30 \mathrm{~s}$, and finally isothermally stressed in the desired conditions or until failure. These tests were performed based on the work processing maps developed by Silva at all ${ }^{19}$ ) under conditions that describe regions of instability. To correlate the microstructure with the deformation conditions, the samples were immediately water-cooled after the deformation was applied. After the standard metallographic procedures, the microstructure treated with nitric acid (65\%) was examined by optical and scanning microscopy.

Electrochemical tests were performed using an Autolab PGSTAT30 potentiostat (Eco Chemie) and a FRA 4.9 frequency analyzer coupled to a microcomputer. The working electrode consisted of ISO 5832-9 stainless steel discs cut out from the useful part of the specimen after the torsion tests, with an area of $0.78 \mathrm{~cm}^{2}$ exposed to $0.9 \% \mathrm{NaCl}$ solution at $298 \mathrm{~K}$. The discs were previously polished with common 300, 400 and 600 grit silicon carbide (SiC) sandpaper, washed with distilled water and ethyl alcohol and dried with a hot air blaster. The electrochemical tests were performed using a classical design of three electrodes with a saturated calomel electrode (SCE) and a platinum electrode working, respectively, as the reference and counter electrodes. The impedance diagrams were obtained in the frequency interval of $50 \mathrm{kHz}$ to $10 \mathrm{MHz}$, with disturbance amplitude of $10 \mathrm{mV}$. All the tests were performed in the open circuit potential at equal $1800 \mathrm{~s}$ time intervals. All the curves were drawn at least three times and the measurements were taken with a stationary electrode.

To investigate the microstructural evolution during hot deformation, isothermal tests were performed that were interrupted at different levels of deformation. In each test, immediately after the deformation was interrupted, the samples were cooled rapidly in water. Different deformation conditions were chosen according to the processing maps, revealing the conditions of workability (Table 2). To check for microstructural heterogeneity, plastic instability and corrosion, the microstructure was characterized by optical microscopy after undergoing electrochemical etching with $65 \%$ nitric acid (HNO3) for 10 to $120 \mathrm{~s}$ at a current of 1.0 $\mathrm{A} / \mathrm{cm}^{2}$ under the sample. This etch was used to reveal grain boundaries, twin boundaries, regions of plastic instability. 


\section{Results and Discussion}

\subsection{Plastic Flow Curve}

Figure 1 shows the plastic flow curves of the ISO 5832-9 austenitic stainless steel obtained by means of the isothermal hot torsion tests at various levels of deformation similar to those of industrial processing. Note that the curves have the typical shape of materials that recrystallize dynamically. Initially there is a region of strain hardening with a change in the curvature as the material is deformed. As deformation continues, a maximum is reached corresponding to the peak stress, thereafter gradually decreasing to an intermediate value for large deformations. Under these conditions one can see that the curves can be separated into three regions, according to their shape: (i) strain softening after the peak, leading the steady state to large deformations; (ii) continu- ous softening, with localized flow; and (iii) plane type flow curve where the stress hardly varies, with deformation showing intense dynamic recovery and reduction of the work hardening rate reaching a saturation stress. ${ }^{20,21)}$

As can be seen from the curves, the stress level increases with increasing strain rate at a given temperature, analogously with the decrease in temperature at a constant strain rate. On the other hand, the evolution of the amount of deformation presents different behaviors. One can see that the deformation peaks of the curves determined at lower levels of temperature and higher strain rates are shifted to the left. In addition, note that after the peak condition, softening is completed only after large deformations. This typical aspect of dynamically recrystallized material is due to the generation of dislocations, twinned crystals and deformation bands when the material is hot deformed, increas-

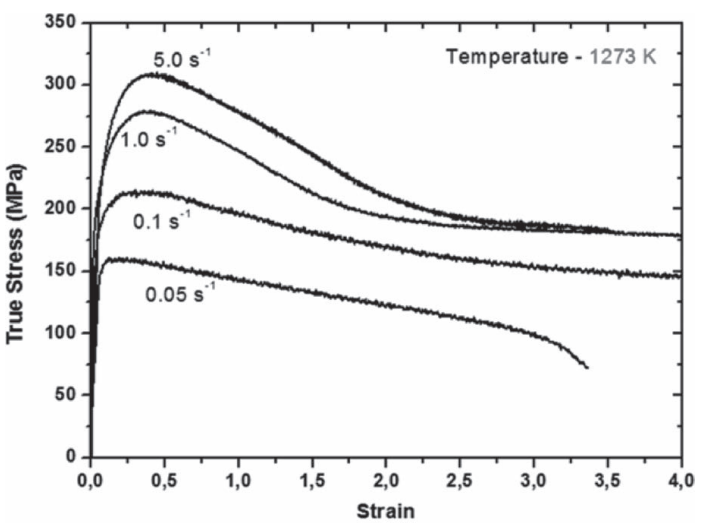

(a)

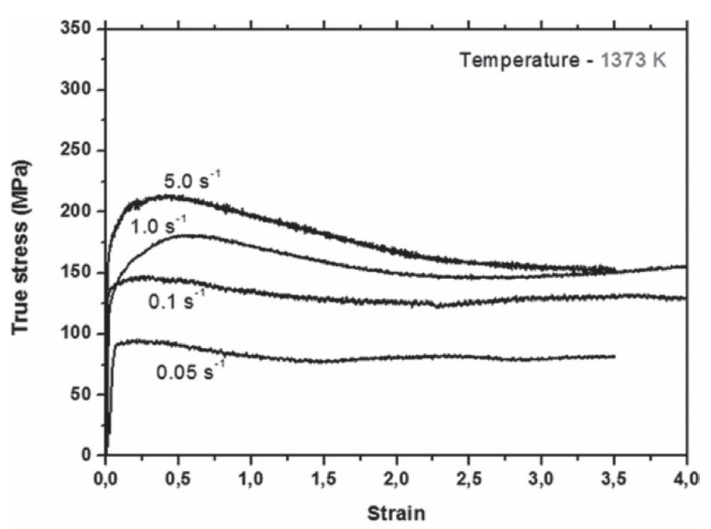

(c)

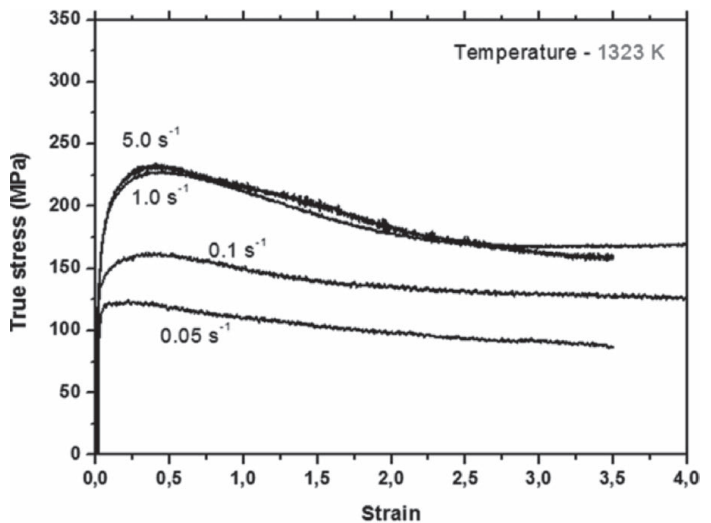

(b)

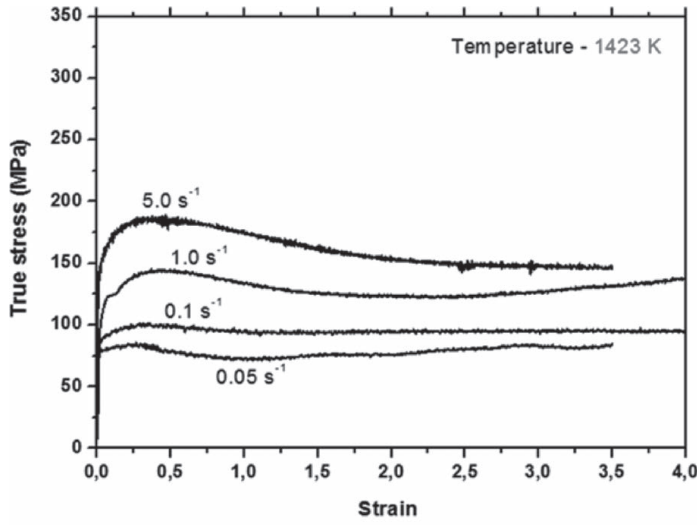

(d)

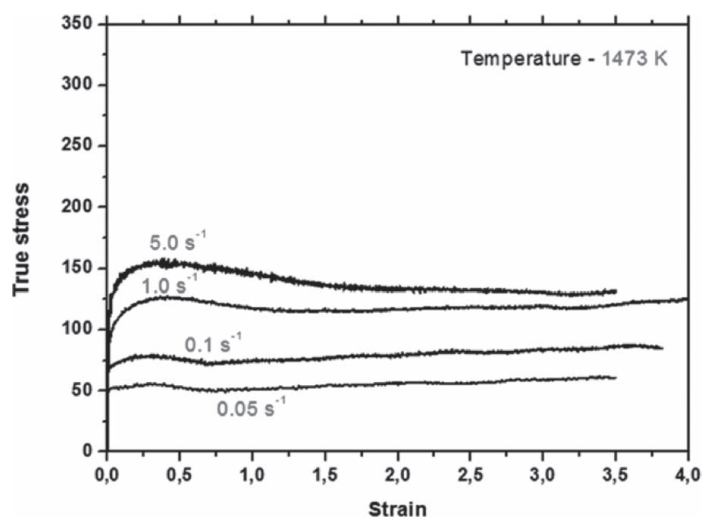

(e)

Fig. 1. Plastic flow curves obtained from continuous isothermal hot torsion tests of ISO 5832-9 steel. (a) $1273 \mathrm{~K}$, (b) $1323 \mathrm{~K}$, (c) $1373 \mathrm{~K}$, (d) $1423 \mathrm{~K}$, (e) $1473 \mathrm{~K}$. 
ing its mechanical strength while reducing the mobility of the dislocations. ${ }^{20,21)}$ This ISO 5832-9 austenitic stainless steel alloy shows moderate SFE with a lower annihilation rate than generation rate; hence, there is a heterogeneous dislocation pile-up that favors the nucleation of new grains.

Steady state stress was reached in all the experiments carried out at high temperatures, despite a few minor differences in the shape of the curves, with the characteristic stress softening behavior resulting from dynamic recrystallization. At high temperatures, the decrease in stress between the peak and steady state stress was relatively minor, while the decrease after the peak was gradual and relatively greater at intermediate temperatures, where the extent of softening promoted by dynamic recovery after the onset of dynamic recrystallization clearly affected the shape of the flow curve. ${ }^{21)}$

As can be seen, at high temperatures and low strain rates, particularly at $0.05 \mathrm{~s}^{-1}$, the shape of the initial part of the plastic flow curves differs from the others. Plastic flow starts at stress levels very close to the values of peak stresses, generating a region of plastic deformation with a relatively low work hardening rate. This behavior is clearly visible at 1473,1423 and $1373 \mathrm{~K}$ with a rate of $0.05 \mathrm{~s}^{-1}$ and at $1473 \mathrm{~K}$ with a rate of $0.5 \mathrm{~s}^{-1}$. This behavior may be associated with increased sensitivity to the stress-strain rate at the deformation temperature, which in turn is linked to the dependence of the level of SFE on temperature. At high temperatures the SFE increases, which reduces the spacing between partial dislocations and makes the recombination process easier, since SFE influences the escalation and slip of dislocations, which are predominant factors in the hot workability of metals.

This high stress level is justified by the high levels of stresses needed for dynamic recrystallization to occur. Observing the curves of Fig. 1(a), 1(b), 1(c), 1(d) and 1(e), one can speculate that higher levels of this ratio are associated with the leftward displacement on the plastic flow curves. This displacement is imposed by higher work hardening rates, thus causing a rise marked by high thermal activation energy, delaying the onset of dynamic recrystallization. This high level of activation energy increases the stress for the onset of recrystallization, which is justified by the presence of precipitates ( $\mathrm{Z}$ phase), increasing the shear stress in the crystal lattice, affecting the material's yield strength, and reducing the SFE while increasing the efficiency of the grain boundaries.

\subsection{Microstructural Analysis}

The different behaviors observed in strain conditions prompted an investigation of the mechanical behavior of this alloy along the curve, with isothermal torsion tests interrupted at different deformation levels. These conditions were chosen based on the work of Silva, ${ }^{19)}$ who constructed the processing maps of this steel, showing its regions of plastic instability and of good hot workability. The microstructures of ISO 5832-9 steel in different deformation conditions enable microstructural phenomena to be classified into three regions: Region I: High strain rate and low temperature, with a predominance of the mechanisms of strain hardening and dynamic recovery, characterized by a structure of elongated pancake-shaped grains. Region II: Presents moderate temperatures and strain rates. In this region, the structure is characterized by partial heterogeneous necklace formation during recrystallization. Region III: Low strain rate and high temperature, where the dynamic recrystallization kinetics is accelerated and necklace formation is not so evident. In this case, the nucleation of new dynamically recrystallized grains starts at very low deformations and the grain boundaries show high mobility, separating from the rapidly evolving serrated region.

Figure 2 shows the microstructure of the ISO 5832-9 steel as received in the annealed condition $(T=1473 \mathrm{~K})$, with an austenitic structure and the presence of precipitates inside the grains that did not dissolve completely during the reheating process. The microstructure consists of equiaxed grains of different sizes with an average diameter of 68 $\mu \mathrm{m}$, indicating that there was grain growth during soaking at $1473 \mathrm{~K}$, and also showing a microstructure with numerous twins.

Isothermal torsion tests interrupted at different levels of deformation were performed to investigate the microstructural evolution during hot deformation. In each test, immediately after interrupting the deformation, the samples were rapidly cooled in water. Seven different deformation conditions were chosen. The first four were chosen in the regions of plastic instability, according to the processing maps: A1 (1 $\left.273 \mathrm{~K} / 0.05 \mathrm{~s}^{-1} / 0.5\right)$; A2 (1 $\left.273 \mathrm{~K} / 1.0 \mathrm{~s}^{-1} / 0.75\right)$; A3 (1 273 $\left.\mathrm{K} / 0.1 \mathrm{~s}^{-1} / 1.3\right)$ and A4 (1 $\left.273 \mathrm{~K} / 0.1 \mathrm{~s}^{-1} / 2.0\right)$, Fig. 3.

In these conditions, in the deformations near the peak, the microstructure is visibly deformed and strongly strain hardened with elongated grains and the emergence of new recrystallized grains generated dynamically along the preexisting boundaries, albeit with no major change in their average size. This microstructural sequence suggests that the onset of recrystallization occurs through the necklace nucleation mechanism. However, although new grains form around the boundaries of old ones, the distribution of these new grains as deformation evolves does not maintain exactly the typical pattern of necklace nucleation. One can see a large concentration of new grains formed around some boundaries of old grains with localized plastic deformation, characterizing a process of localized flow with formation of adiabatic shear bands, which generates plastic instability in the steel, affecting the shape of the curve. Also, it is

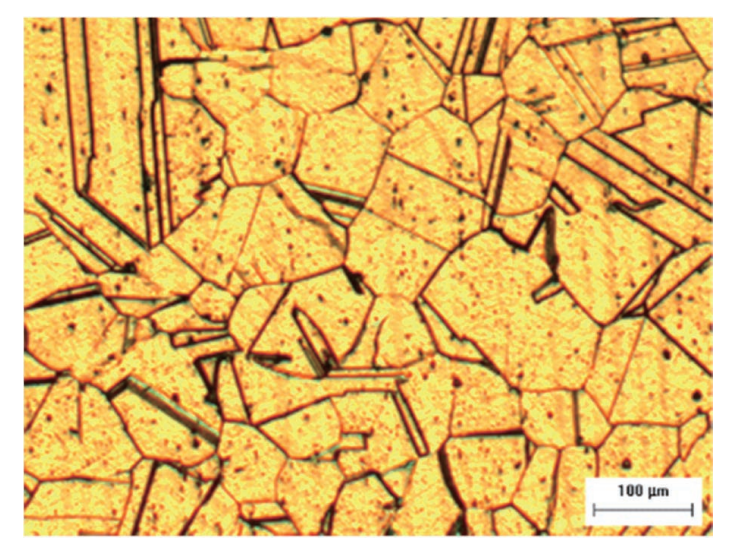

Fig. 2. Initial microstructure of a sample of ISO 5832-9 steel reheated to $1473 \mathrm{~K}$ and held there for $300 \mathrm{~s}$ before cooling in water. (Online version in color.) 
worth noting that after large deformations the microstructure still contains many old deformed grains (pancake-shaped), indicating that even in large deformations, dynamic recrystallization is not yet complete and occurs heterogeneously, even with steady-state stress deformations, and the average size of dynamically recrystallized grains is larger than the average size observed in the early stages, when nucleation with necklace formation prevails.
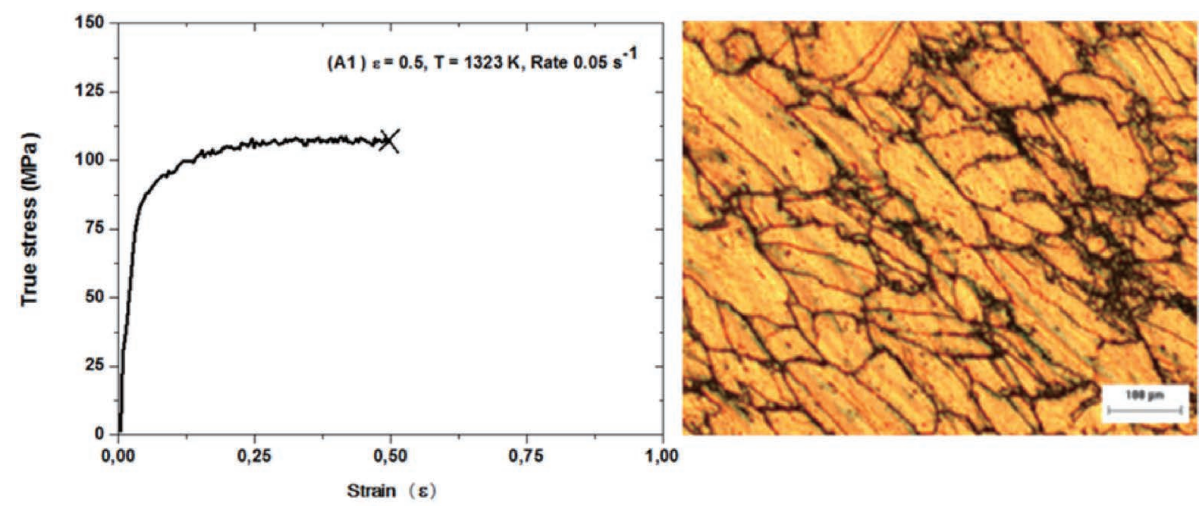

(a)
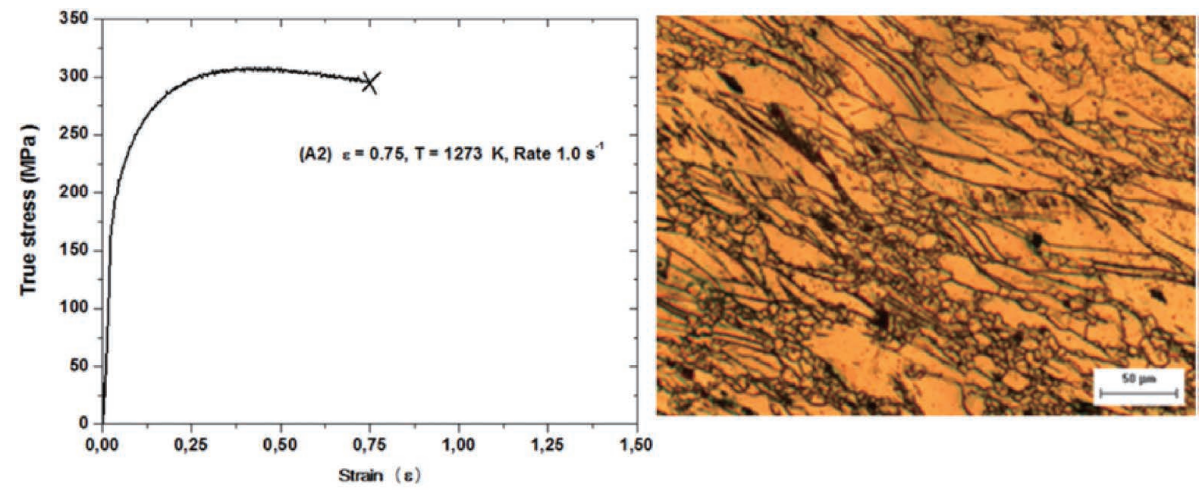

(b)

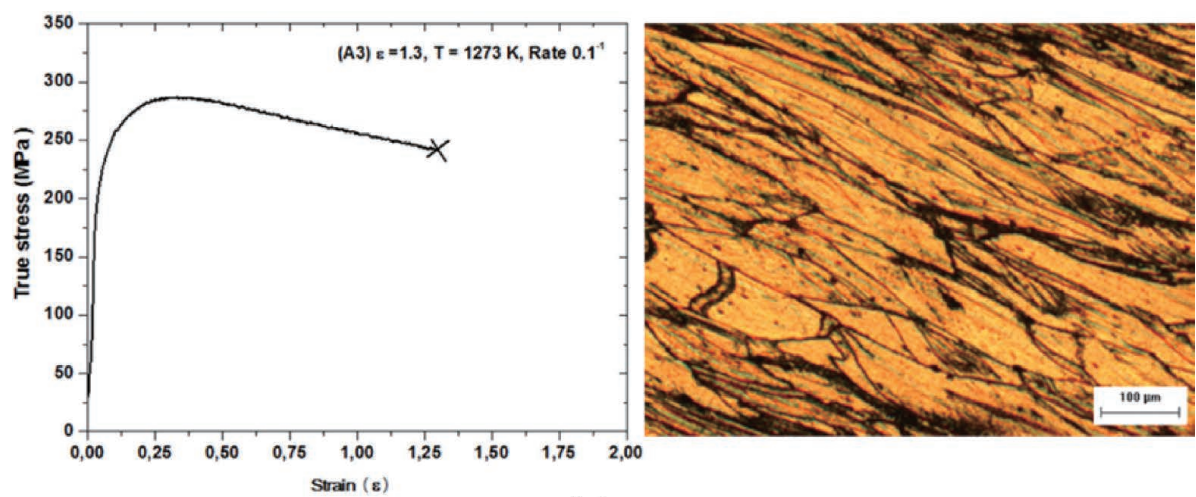

(c)

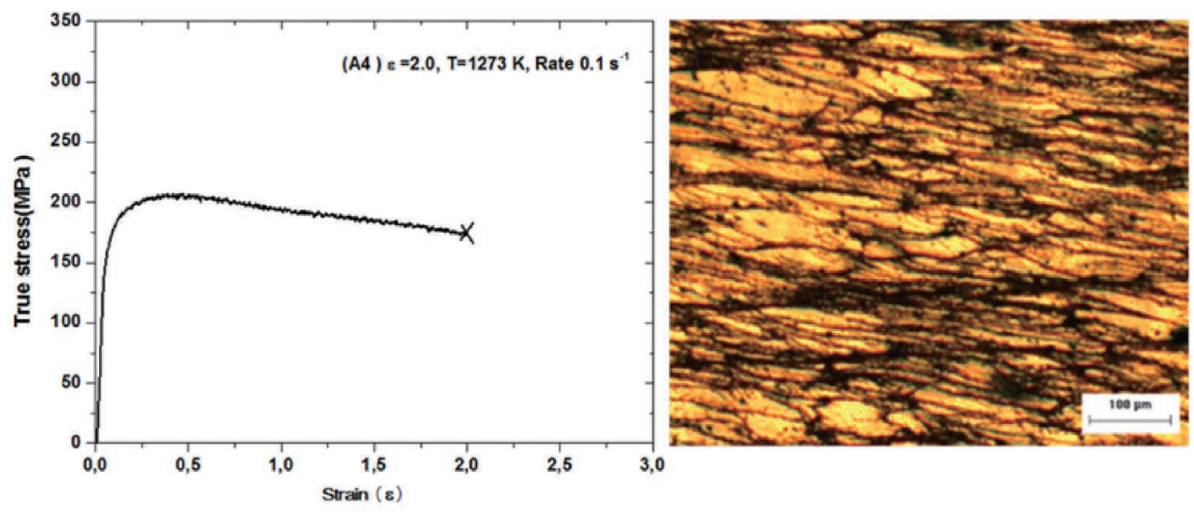

(d)

Fig. 3. Microstructure of ISO 5832-9 steel samples deformed in the conditions of plastic instability. (a) sample A1, (b) sample A2, (c) sample A3, (d) sample A4. (Online version in color.) 
In the second set of conditions, outside the region of instability, A5 (1 $\left.323 \mathrm{~K} / 0.5 \mathrm{~s}^{-1} / 4.0\right)$ and A6 (1 $473 \mathrm{~K} / 1$ $\mathrm{s}^{-1} / 2.0$ ), Fig. 4, the plastic flow curves are in a state of stationary-phase stress and dynamic recrystallization develops with necklace formation. Note that the microstructure appears strongly deformed, showing elongated pancakeshaped grains with intense dynamic recovery and the development of a few serrated grain boundaries, generating the first dynamically recrystallized grains along boundaries due to the dependence of the mobility of dislocations on the conditions of deformation and SFE. At high levels of deformation, the material is strongly recrystallized, as observed in the SEM/EBSD analysis of R.C. Sousa, ${ }^{20)}$ who reported that more than $90 \%$ of the microstructure was recrystallized. However, the microstructure still shows the presence of pre-existing deformed grains, with a delay in the dynamic recrystallization kinetics. At the maximum applied strain of 4.0, which is higher than steady-state deformation, the microstructure still contains some pre-existing deformed grains and shows a larger average recrystallized grain size with delayed dynamic recrystallization shown in Fig. 4. As a result of the delay in dynamic recrystallization, the recovery process promoted by dynamic recovery through deformation minimizes the stored energy, which justifies the necklace formation, suggesting a low nucleation rate with partial dynamic recrystallization.

Lastly, in condition A7 (1 $\left.323 \mathrm{~K} / 0.1 \mathrm{~s}^{-1} / 4.0\right)$, Fig. 5, note that the microstructures obtained show some serration at the grain boundaries. Unlike the previous microstructures, preferential nucleation at the boundaries is not visible, at least not clearly, suggesting that it may occur conventionally, i.e., both boundary and intra-grain nucleation. At higher deformations a few serrated grain boundaries are visible, most of them showing a predominance of elongations, while at the highest deformations the microstructure is almost entirely recrystallized, since there are still some pre-existing
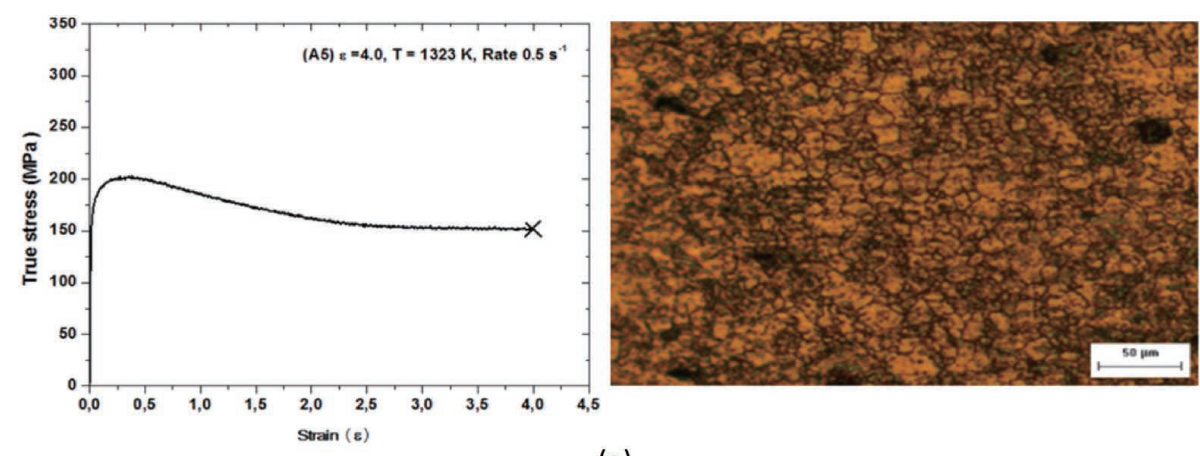

(a)
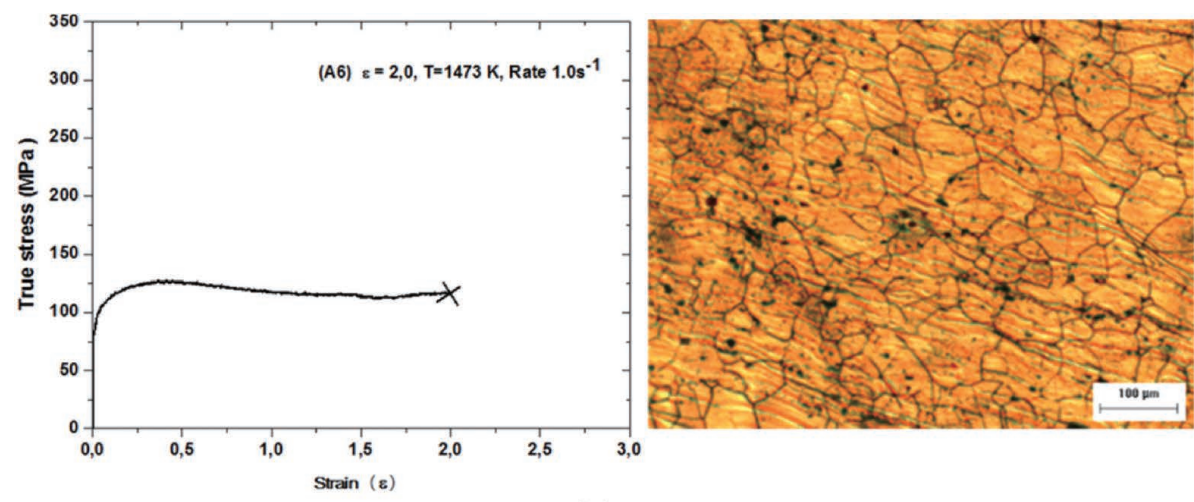

(b)

Fig. 4. Microstructure of ISO 5832-9 steel samples deformed outside of the conditions of plastic instability. (a) sample A5, (b) sample A6. (Online version in color.)

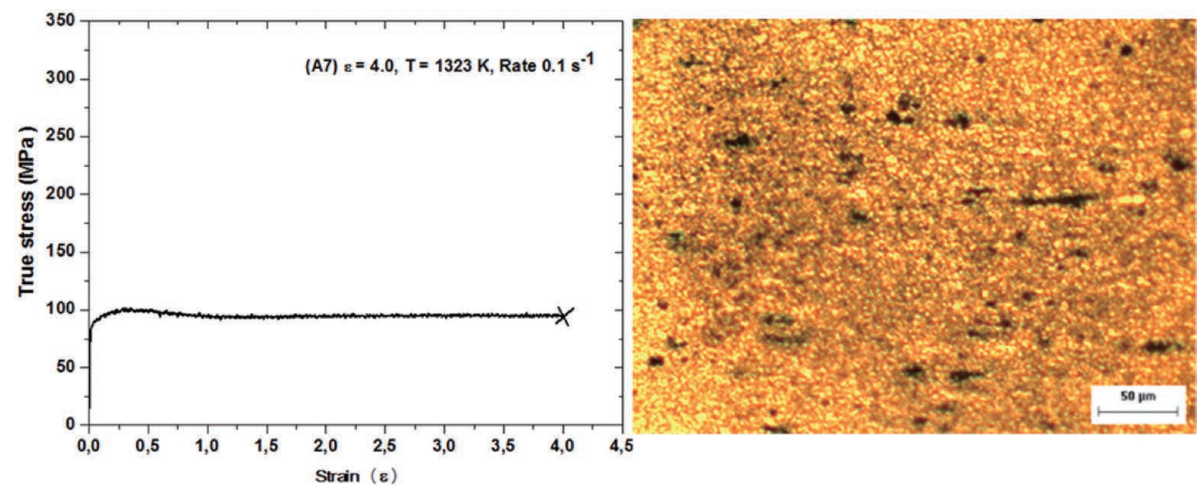

Fig. 5. Microstructure of the samples of ISO 5832-9 steel deformed in the condition of plastic instability - sample A7. (Online version in color.) 
deformed grains, confirming that the recrystallization process is inhomogeneous. In this steady state phase, the average grain sizes measured by XRD according to the E112 standard for the A5, A6 and A7 condition are, respectively, $6.0 \mu \mathrm{m}, 20 \mu \mathrm{m}$ and $5.0 \mu \mathrm{m}$, and are smaller than the initial grain size of $68 \mu \mathrm{m}$, since the average grain size decreases at lower temperatures. The result of dynamic recrystallization is the substitution of a microstructure with initially large grain sizes for one with considerably smaller ones.

\subsection{Analysis of the Electrochemical Tests}

\subsubsection{Open Circuit Potential}

Figure 6 depicts the curves of corrosion potential variation as a function of the immersion time of ISO 5832-9 steel at room temperature. The results indicate that after $1800 \mathrm{~s}$ of immersion in a $0.9 \% \mathrm{NaCl}$ solution, the potential of all the samples was stabilized, without variation at the beginning of the tests. However, as the immersion time increased, the samples showed values close to the corrosion potential $\left(\mathrm{E}_{\mathrm{ca}}=0,3 \mathrm{mV}\right)$ in both regions, characterizing a decrease in passivity of the material due to nucleation and stable propagation of pitting corrosion, marked by an increase in corrosion current density in a small region at the surface of the material.

In addition, note that on the curve for condition A1, stabilization proceeds coherently, with a slight variation in the

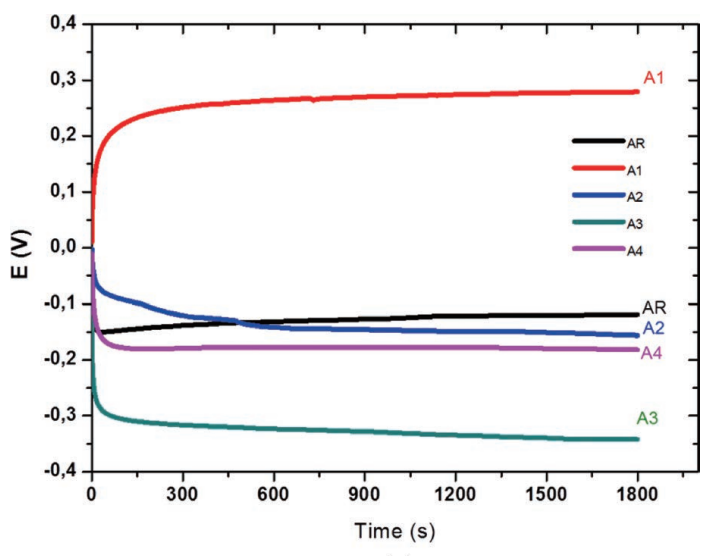

(a)

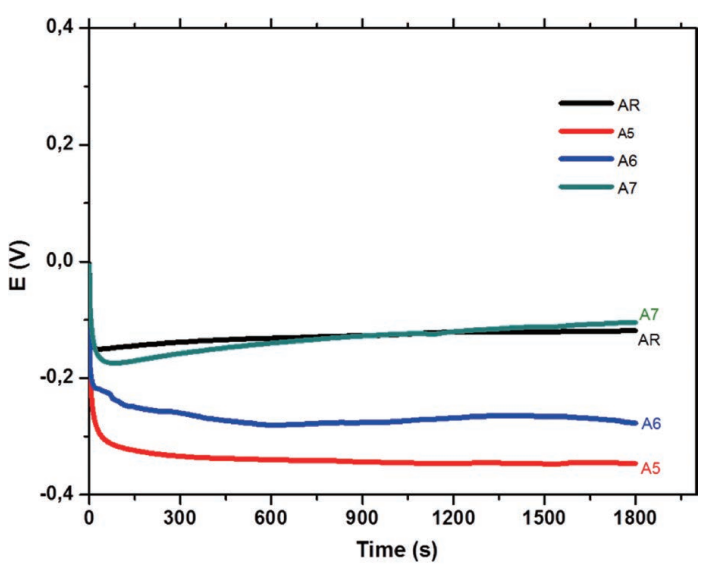

(b)

Fig. 6. Variation of the corrosion potential as a function of the samples' immersion time: (a) plastic instability regions A1, A2, A3, A4 and AR (as received); (b) outside the region of plastic instability - A5, A6, A7, AR. (Online version in color.) slope toward a more noble potential, showing a tendency for the formation of a passive layer in the electrolyte. The fact that curves A2 to A6 developed with lower potentials indicates dissolution of the film in the electrolytic medium, generating a decrease in the potential as a function of time in the test, with loss of the passive layer of the material, favoring a convergence towards corrosion in this condition.

\subsubsection{Electrochemical Impedance Spectroscopy}

The electrochemical impedance spectroscopy (EIS) tests of the ISO 5832-9 steel samples performed in the regions of plastic instability and stability showed similarities with the results shown in the graphs of open circuit potential, revealing the same tendency for corrosion resistance, Fig. 7. The Bode plots demonstrate this trend, with the samples in conditions A3 and A5 exhibiting straight lines with lower slopes, while the plots of samples A1 and A7 show marked slopes, thus indicating a higher tendency for corrosion resistance (Fig. 7(a)). Samples A3 and A5 (Fig. 7(b)) showed the smallest phase angles, indicating a tendency for less protection of the material. In contrast, sample A1 presented one of the higher phase angles and A7 the highest angle, indicating a greater tendency for corrosion resistance. In general, with regard to the Bode plots, samples A2, A4, A5 and A6 showed intermediate conditions relative to the others, with a higher tendency for protection than the as received sample. Moreover, the condition of sample A7 exhibited the best tendency for corrosion protection.

The Nyquist diagram in Fig. 8 shows the formation of a single capacitive arc process corresponding to a charge transfer in the double electric layer. Over time, the film becomes stronger and the arc is not complete in this region of analysis. Figures 7 and 8 indicate that the results obtained from the Bode plots correspond to the Nyquist diagrams, where samples in conditions A3 and A5 showed the highest tendency for arc formation. This indicates the lower corrosion resistance of these two samples within their respective regions, while sample A7 showed the lowest tendency to form a capacitive arc, indicating greater corrosion protection of these samples.

The Bode, Nyquist and EIS diagrams show similar results, revealing an unfavorable difference in the regions of plastic instability in comparison to the as received samples. An analysis of the EIS diagrams leads to the conclusion that the A7 samples showed the best corrosion protection results in both the Bode and Nyquist diagrams. The higher corrosion resistance of the steel in the conditions of good workability is attributed to the increased stability of the passive film, which is probably favored by the presence of nitrogen in interstitial solid solution, giving it greater chemical and mechanical stability. On the other hand, samples A3 and A5 exhibited the worst responses in terms of corrosion protection in their respective regions, in view of the experimental impedance modulus values obtained.

\subsubsection{Cyclic Polarization}

The purpose of the potentiodynamic cyclic polarization tests was to obtain information about the alloy's corrosion resistance and ascertain the stability of the layer on the steel surface. The Tafel extrapolation graphs (Fig. 9) indicate that the as received (AR) sample has the noblest potential of all 
ISIJ International, Vol. 55 (2015), No. 3
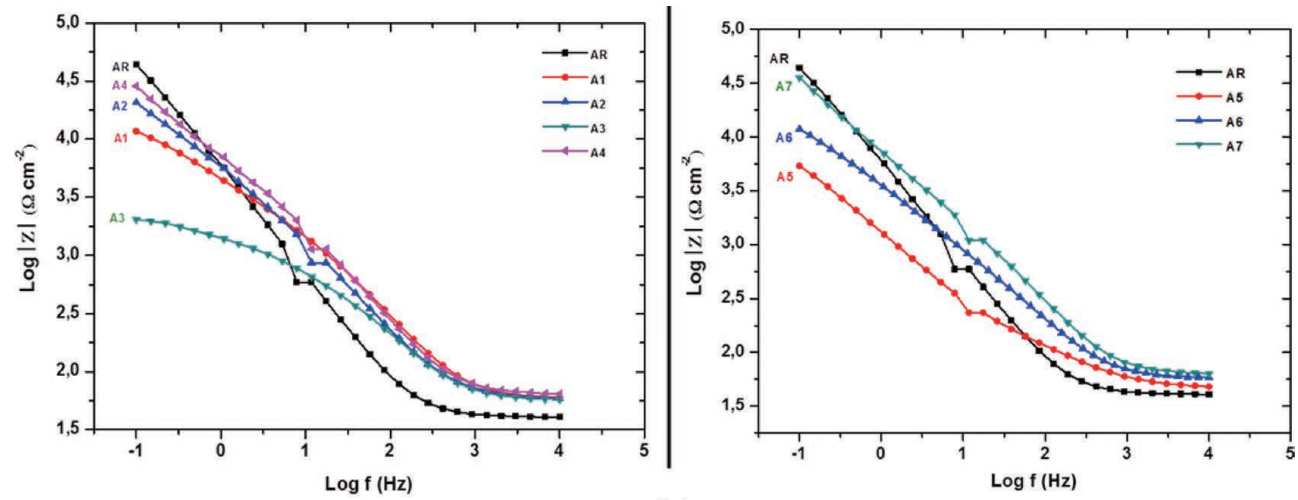

(a)
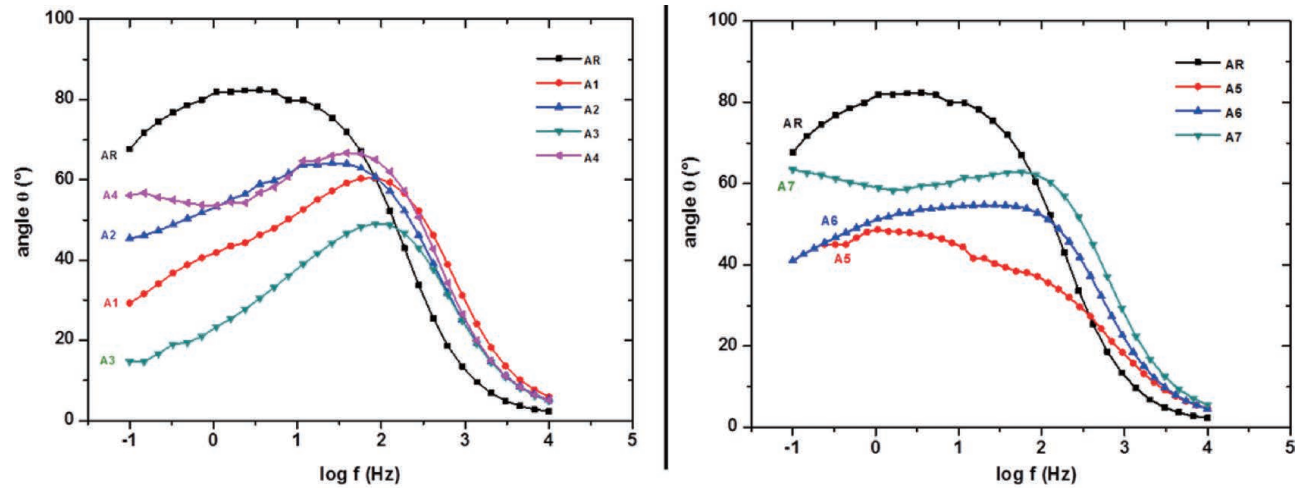

(b)

Fig. 7. Bode plots of samples $\mathrm{A} 1$ to $\mathrm{A} 7$ : (a) variation of $\log |\mathrm{Z}|$ vs $\log \mathrm{f}$, (b) variation of $\theta$ vs $\log \mathrm{f}$. (Online version in color.)
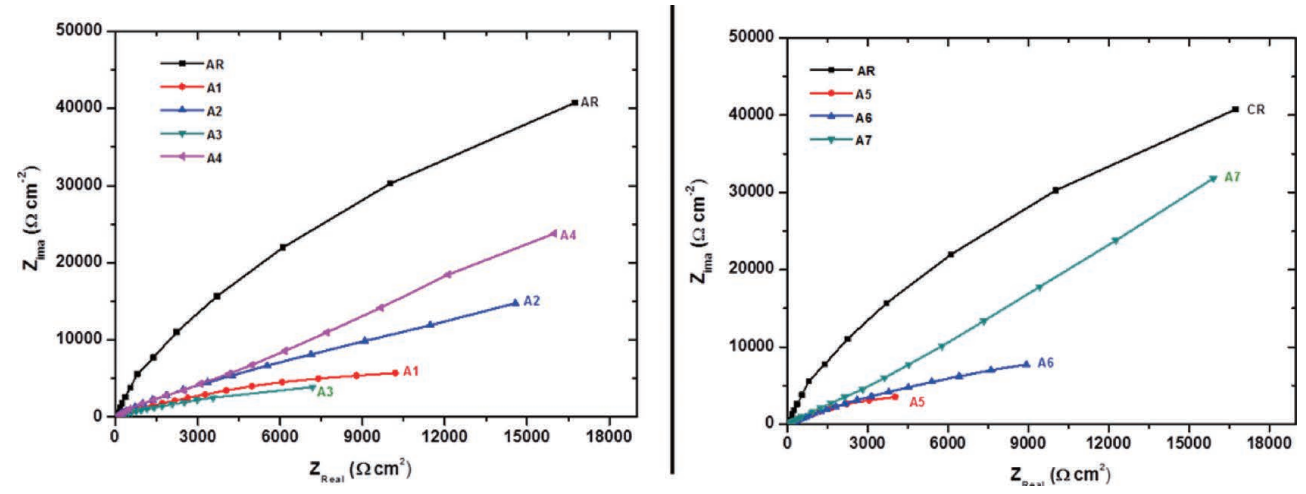

Fig. 8. Nyquist diagrams of samples A1 to A7. (Online version in color.)

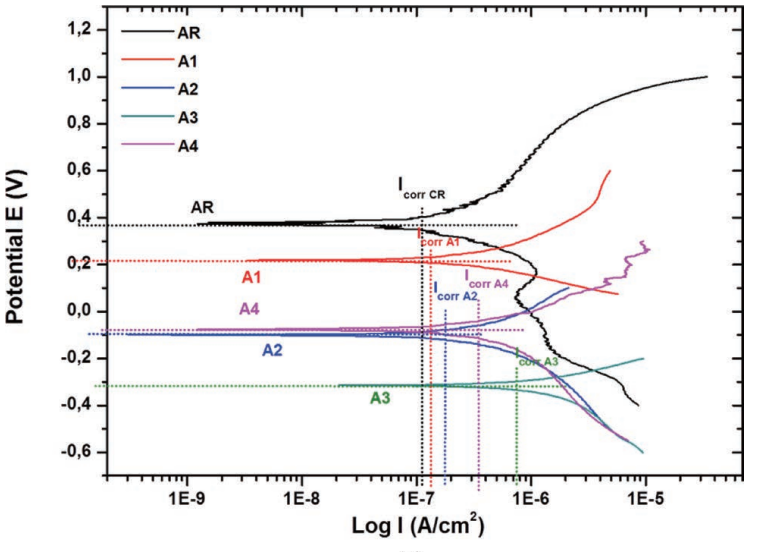

(a)

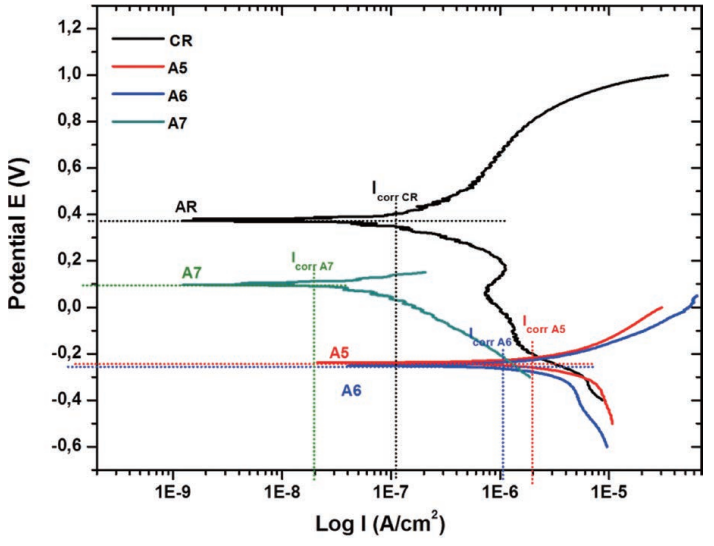

(b)

Fig. 9. Cyclic polarization curve with Tafel extrapolation: (a) region of plastic instability, samples A1, A2, A3, A4 and A5, (b) outside the region of plastic instability, samples A6, A7 and A8. (Online version in color.) 
Table 3. Parameters evaluated in the electrochemical tests by the Tafel extrapolation method.

\begin{tabular}{cccc}
\hline & $\mathrm{I}_{\text {corr }}(\mu \mathrm{A})$ & $\mathrm{E}_{\text {corr }}(\mathrm{mV})$ & $\mathrm{T}_{\mathrm{C}}\left(\mathrm{mm}^{\mathrm{year}}{ }^{-1}\right)$ \\
\hline $\mathrm{AR}$ & 0.106 & 0.366 & 0.001388 \\
$\mathrm{~A} 1$ & 0.135 & 0.129 & 0.001768 \\
$\mathrm{~A} 2$ & 0.178 & -0.102 & 0.002332 \\
$\mathrm{~A} 3$ & 0.713 & -0.314 & 0.009339 \\
$\mathrm{~A} 4$ & 0.471 & -0.079 & 0.006169 \\
$\mathrm{~A} 5$ & 2.35 & -0.23 & 0.030781 \\
$\mathrm{~A} 6$ & 0.959 & -0.248 & 0.012561 \\
A7 & 0.021 & 0.09 & 0.000275 \\
\hline
\end{tabular}

the samples. Among the conditions under study, samples A1 and A7 showed the noblest potential in the regions of stability and instability, respectively, indicating a higher corrosion resistance than the other samples. As for the corrosion currents, samples A1, A7 and AR clearly exhibited the weakest corrosion currents, which is also an indication of the good corrosion resistance of these samples. However, samples A3 and A5 presented the lowest corrosion potentials and strongest corrosion currents, characterizing a greater tendency for corrosion in their respective regions in relation to the other conditions, which is consistent with the results obtained in the other tests.

Table 3 lists the data obtained from the electrochemical cyclic polarization tests using the Tafel extrapolation method. As can be seen, almost all the samples showed low corrosion rates, indicating the good corrosion resistance of the alloy. Note that all the samples of the regions of plastic instability exhibit higher corrosion rates than the as received (AR) sample, with sample A3 showing the highest corrosion rate within this region of instability. In the region of plastic stability, sample A7 presented the lowest corrosion rate among all the samples.

It should be noted that inside the region of instability, sample A1, with its marked dynamic recovery (DRV), shows a greater tendency for corrosion than samples A5 and A6 in the regime of dynamic recrystallization (DRX). Thus, the structure with fewer boundaries should respond better to corrosion phenomena, because the smaller the grain size the higher the energy at the boundaries resulting from the intergrain deformation phenomenon and the greater the number of boundary related defects. On the other hand, eventual impurities and particle precipitates are relocated to the boundaries, forming a larger number of corrosion sites in the coarser grained structure and thus creating a difference in corrosion potential $\left(\mathrm{E}_{\mathrm{c}}\right)$ between the boundaries and adjacent regions. This explains the microstructural heterogeneities that lead to the development of cracks along the grain boundaries and the resulting strain rupture of the material, as shown in the plastic flow curves that do not reach the maximum applied strain. However, sample A1, with its structure of strain elongated grains, presents a corrosion current, $\mathrm{I}_{\text {Corr }}$, of about $0.1 \mu \mathrm{A} / \mathrm{cm}^{2}$, in contrast to the
$\mathrm{I}_{\text {Corr }}$ of $0.02 \mu \mathrm{A} / \mathrm{cm}^{2}$ of the refined structure of sample A7. With respect to the $\mathrm{E}_{\mathrm{c}}$ of sample $\mathrm{A} 1$, the dispersion of values is not significant, but it shows a nobler potential than A7, indicating that even in the condition of instability there is a lower corrosion rate in this region, even though sample A7 shows a lower corrosion rate.

\section{Conclusions}

The continuous isothermal hot torsion tests showed that plastic yield stress is sensitive to the deformation parameters. The peak stress decreases with increasing temperature and reduction of the strain rate with a high dynamic recovery rate with elongated grains, stress build-up and deformation bands, generating regions of localized flow. These regions of plastic instability (samples A2, A3, A4, A5 and A6) show a higher degree of corrosion than the as received (AR) samples, which is attributed to the reduction in instability of the passive film. The regions of high temperature and low strain rate present good workability, with a refined final microstructure containing delayed dynamically recrystallized grains, without evidence of localized corrosion, which is favored by the presence of nitrogen in solid solution.

\section{Acknowledgments}

The authors gratefully acknowledge FAPEMA, CNPq and CAPES (Brazil) for their financial support of this work.

\section{REFERENCES}

1) M. Navarro, A. Michiardi, O. Castaño and J. A. Planell: J. Roy. Soc. Int., 5 (2008), 1137.

2) E. J. Giordani, V. A. Guimarães, T. B. Pinto and I. Ferreira: Int. J. Fadigue, 26 (2004), 1129.

3) C. Örnhagen, J. O. Nilsson, H. Vannevik and J. Biomed: Mater. Res., 31 (1996), 97.

4) M. C. Mataya, E. R. Nilsson, E. L. Brown and G. Krauss: Metall. Mater. Trans. A, 34A (2003), 1683.

5) A. Laasraoui and J. J. Jonas: Metall. Mater. Trans. A, 22A (1991), 1545 .

6) A. S. Taylor and P. D. Hodgson: Mater. Sci. Eng. A, 528 (2011), 3310.

7) U. F. Kocks and H. Mecking: Mater. Sci., 48 (2003), 171.

8) H. J. McQueen: Mater. Sci. Eng. A, 203 (2003), 387.

9) M. El Wahabi, J. M. Cabrera and J. M. Prado: Mater. Sci. Eng. A, 343 (2003), 116.

10) R. E. Schramn and R. P. Reed: Metall. Trans. A, 6 (1975), 1345.

11) E. J. Giordani, A. M. Jorge, Jr. and O. Balancin: Scr. Mater., 55 (2006), 743.

12) J. J. Jocobs: J. Bone Surg., 80A (1998), No. 2, 268.

13) S. Venugopal and P. V. Sivaprasad: J. Mater. Eng. Perform., 12 (2003), 675.

14) H. Ziegler: Progress in Solid Mechanics, Vol. 2, ed. by I. N. Sneddon and R. Hill, John Wiley and Sons, New York, (1963), 93.

15) Y. V. R. K. Prasad and S. Sasidhara: Hot Working Guide: A Compendium of Processing Maps, ASM International, Materials Park, $\mathrm{OH},(1997)$.

16) Y. V. R. K. Prasad: J. Mater. Eng. Perform., 12 (2003), No. 6, 674.

17) Y. V. R. K. Prasad: J. Mater. Eng. Perform., 12 (2003), No. 6, 656.

18) D. S. Fields and W. A. Backofen: Proc. Am. Soc. Test. Mater. (ASTM), 57 (1957), 1259.

19) E. S. Silva, R. C. Sousa, A. M. Jorge, Jr. and O. Balancin: Mater. Sci. Eng. A, 543 (2012), 69.

20) R. C. Souza, E. S. Silva, A. M. Jorge, Jr., J. M. Cabrera and O. Balancin: Mater. Sci. Eng. A, 582 (2013), 96.

21) S. F. Rodrigues, E. S. Silva, G. S. Reis, R. C. Sousa and O. Balancin: Mater. Resert., 17 (2014), No. 2, 436. 